\title{
КРИМИНОЛОГИЧЕСКИЕ АСПЕКТЫ ПРАВОВОГО СОЗНАНИЯ КРЕСТЬЯНСТВА ЗАПААНОГО РЕГИОНА РОССИИ НА РУБЕЖЕ XIX-XX ВЕКОВ
}

\author{
В.В. Кулачков ${ }^{1}$, Т.Л. Музычук ${ }^{2}$ \\ ${ }^{1}$ Брянский государственный инженерно-технологический университет, г. Брянск, Российская Федерация \\ ${ }^{2}$ Байкальский государственный университет, г. Иркутск, Российская Федерация
}

\author{
Информация о статье \\ Дата поступления \\ 2 сентября 2016 г. \\ Дата принятия в печать \\ 25 июня 2017 г. \\ Дата онлайн-размещения \\ 29 сентября 2017 г.

\section{Ключевые слова} \\ Крестьянство; Западный регион \\ России; правовое сознание; \\ криминологические аспекты; \\ самосуд; обычное право
}

\begin{abstract}
Аннотация. Статья посвящена рассмотрению криминологических аспектов правового сознания крестьянства Западного региона России на рубеже XIX-XX вв. Авторы отмечают, что наблюдается достаточно большое внимание к правовым проблемам сельской повседневности. Криминологические аспекты правового сознания крестьян выражались в своеобразном отношении жителей деревни к преступлениям и различным правонарушениям. Фундаментальной основой правового сознания крестьян было так называемое обычное право. При этом нравы и обычаи крестьянства находились в неразрывной связи с правовыми принципами. Наступление божьей кары считалось неизбежным в крестьянской среде, особенно при отсутствии реального наказания в жизни. Крестьянское правовое сознание имело двойственный характер, что выражалось в разделении на "своих» и "чужих». Специфическое понимание законности отчетливо проявлялось в крестьянских взглядах на лесные богатства. Крестьяне считали, что лес - это общее достояние, принадлежит всем, но это противоречило формальной законности. В самосудах наиболее ярко проявлялись криминологические аспекты правового сознания крестьян Западного региона России, чему способствовали распространенные конокрадство и воровство. Консерватизм и архаичность правового сознания формировали приверженность крестьян многовековым традициям и обычаям.
\end{abstract}

\section{CRIMINOLOGICAL ASPECTS OF LEGAL CONSCIOUSNESS OF PEASANTS IN THE WESTERN REGION OF RUSSIA AT THE TURN OF THE $19^{\text {th }}-20^{\text {th }}$ CENTURIES}

\author{
Vadim V. Kulachkov', Tatyana L. Muzychuk ${ }^{2}$ \\ ${ }^{1}$ Bryansk State Engineering-Technological University, Bryansk, the Russian Federation \\ ${ }^{2}$ Baikal State University, Irkutsk, the Russian Federation
}

\author{
Article info \\ Received \\ 2016 September 2 \\ Accepted \\ 2017 June 25 \\ Available online \\ 2017 September 29

\section{Keywords} \\ The peasantry; the Western region \\ of Russia; legal consciousness \\ criminological aspects; vigilantism; \\ customary law
}

\begin{abstract}
The article examines the criminological aspects of legal consciousness of peasants in the Western region of Russia at the turn of the $19^{\text {th }}-20^{\text {th }}$ centuries. The authors note that there is now a considerable interest in the legal issues of everyday rural life. The criminological aspects of peasants' legal consciousness were manifested through a specific attitude of villagers to crimes and various offences. The fundamental basis of peasants' legal consciousness was the so-called customary law. Besides, the mores and customs of peasants were inextricably connected with legal principles. They considered divine retribution to be inevitable, especially if there was no actual punishment in real life. Peasants' legal consciousness had a dual character manifested in the differentiation between "ours» and «theirs». The specific understanding of legality was clearly seen in peasants' views of forest resources. They believed that forests were common property and belonged to everybody, which contradicted formal laws. Vigilantism most conspicuously manifested criminological aspects of legal consciousness of peasants in the western region of Russia, and the widespread horse stealing and theft contributed to that. The conservative and archaic character of legal consciousness shaped the commitment of peasants to old ways and customs.
\end{abstract}

В настоящее время отмечается достаточно большое внимание к проблемам эволюции правового положения крестьянства. В частно- сти, представляют исследовательский интерес криминологические аспекты правового сознания сельских жителей. Целью данной статьи яв- 
ляется изучение криминологических аспектов правового сознания крестьян Западного региона России на рубеже XIX-XX вв.

В статье используются материалы Западного региона России (территория современных Смоленской, Брянской и Калужской областей). Данный выбор обусловлен как географической близостью, так и изменением административных границ в ходе развития регионов. Очевидно, что это оказывало свое влияние на эволюцию криминологических аспектов правового сознания крестьянства. Под криминологическими аспектами в данной статье подразумевается специфическое отношение сельских жителей к преступлениям и различным правонарушениям.

Изучение криминологических аспектов правового сознания крестьянства невозможно без выяснения места и роли права в жизни общества. Традиционно под правовым сознанием подразумеваются осознаваемые личностью и обществом отношения по поводу существовавшей и существующей системы права. Так, И.Е. Фарбер понимает под правосознанием «форму общественного сознания, представляющую собой совокупность правовых взглядов и чувств, обладающих нормативным характером и включающих в себя как знание правовых явлений, так и их оценку с точки зрения справедливости, а также правовые требования, отражающие экономические и политические потребности и интересы общественного развития» $[1$, с. 96]. Г.С. Остроумов считает, что «правосознание - это представления, понятия, идеи, выражающие потребности в опосредовании поведения людей государственно-правовой волей» [2, с. 43].

Следует отметить, что правовое сознание крестьян непосредственно воплощалось в нормах так называемого обычного права. Обычное право есть такая форма права, которая призвана регулировать поведение людей на основе ранее сложившихся стереотипов. Этимологически дефиниция понятия «обычное право» связана с существительным «обычай» - «стереотипный способ поведения, который воспроизводится в определенном обществе или социальной группе и является привычным для их членов» [3, с. 829-830].

Обычай относится к сфере устной традиции и тесно связан с правовой мифологией. Источниками возникновения обычаев становились распоряжения власти, судебные решения и про- стое заимствование, которое видоизменялось народной мыслью и становилось нормой для разрешения конфликтных ситуаций. Например, М. Блок считал обычай «живым источником права» [4, с. 172]. В народном быту обычаи выступали хранителями многовекового опыта, в том числе правового, поэтому крестьяне к ним относились бережно: «Обычай не клетка - не переставишь» [5, с. 154]. Многие обычаи приобрели силу привычки и исполнялись рефлекторно по причине древности происхождения и продолжительности действия. Для народного быта было характерно разнообразие обычаев. «У Сидора обычай, а у Карпа свой», «Что город, то норов, что деревня, то обычай», «У всякого попа свой обиход", - говорили в народе [там же].

Рассмотрением различных аспектов правового сознания крестьянства занимались как отечественные, так и зарубежные ученые. В частности, ценный материал содержат работы В.В. Тенишева, в которых отражаются основные черты правового сознания крестьянства Западного региона России [6-8]. Изучению социально-политического и правового положения крестьян был посвящен сборник статей, основанный на материалах XVIII сессии Всесоюзного симпозиума по изучению проблем аграрной истории (25-29 сентября 1980 г.) [9].

Коллективная работа П.С. Кабытова, В.А. Козлова, Б.Г. Литвака «Русское крестьянство: этапы духовного освобождения» продолжила и углубила анализ крестьянского общественного сознания [10]. Феномен правового сознания нашел свое выражение в работах Е.А. Белканова [11] и В.П. Малахова [12]. На проходившей в 1994 г. в Москве международной конференции обсуждались проблемы формирования крестьянского менталитета и общинного типа сознания, различные аспекты этнокультурного проявления крестьянского мировоззрения [13]. М.М. Громыко указывала на юридическую грамотность крестьян - знание ими официального законодательства и умение им воспользоваться [14].

Западные исследователи также уделяли внимание эволюции правового сознания крестьянства. Различные аспекты обычного права находились в фокусе исследовательского интереса многих зарубежных ученых [15-19]. В частности, С. Фрэнк отмечал, что «самосуд в русской деревне конца XIX - начала XX вв. не был беззаконным насилием. Это была акция крестьянской общины, направленная на пресечение действий, которые угрожали нарушить 
традиционные социальные отношения или нанести урон хозяйству деревни» [20]. Д. Бербанк пришла к выводу, что волостные суды сыграли важную роль в приобщении крестьянства к правовой культуре [21; 22]. Т. Шанин резюмировал, что «жизнь крестьянского двора продолжалась по старинке, согласно глубоко укоренившемуся крестьянскому обычаю» [23, с. 346].

Таким образом, в отечественной и зарубежной историографии правовое сознание рассматривалась в плане взаимоотношений крестьянства и власти, представлений крестьян о юстиции, о правосудии и справедливости, преступлении и наказании, законах и законности. Однако остаются пробелы в смысле изучения региональной специфики криминологических аспектов правового сознания, что актуализирует исследовательскую работу в данном направлении.

Следует сказать, что основная масса русского крестьянства на рубеже XIX-XX вв. была безграмотна, поэтому криминологическая составляющая правового сознания проявлялась в различных традициях и обрядах. В частности, существовал обычай одаривать и угощать арестантов на Пасху или другие большие праздники. Например, «в Талызинской волости Орловской губернии на «Велик день» звали к себе "разговляться» всех, кто сидел в это время под арестом в волостной тюрьме» [24, с. 677-678]. Крестьяне Смоленской губернии «на преступника, даже на убийцу, смотрели как на несчастного и в посильных приношениях выражали свое сострадание к ним: приносили в тюрьму яйца, баранину, поросят, пироги и проч. Если встречали где-нибудь в лесу бродягу или арестанта, то из чувства сострадания не трогали его» ${ }^{1}$.

Нравы и обычаи крестьянства находились в неразрывной связи с правовыми принципами, что подтверждается архивными документами. Так, корреспондент Лашманов в 1897 г. (с. Пушкино Калужской губернии) сообщал, что «два года тому назад в Зайцево один крестьянин застрелил из ревности свою жену и покушался на самоубийство. Крестьяне считали ревность за смягчающее вину обстоятельство, поэтому когда этого крестьянина приговорили к арестантским ротам на 2 года, то мнение крестьян разделилось: старики не могли понять, почему он не сослан на каторгу, молодежь относилась более снисходительно к преступнику. Брат осужденного хлопотал о выключении его из общества из

${ }^{1}$ Государственный архив Российской Федерации (ГАРФ). Ф. 586. Оп. 1. Д. 120. Л. 58. корыстных целей, чтобы сделаться единственным хозяином дома и земли» ${ }^{2}$.

Информатор Лебедев в мае 1899 г. (Калужская губерния и уезд) писал, что «год назад был следующий случай. Один крестьянин, женив своего пасынка, отослал его на заработки, чтобы беспрепятственно жить с его женой. Отношения между ним и женой его пасынка, имея преступный характер, не замедлили открыться обществу. Последнее, считая себя обиженным и не желая иметь в своей среде подобного члена, составило сход, на котором постановило: потребовать от падчерицы, чтобы она подала жалобу на своего сожителя, в противном случае общество сделает приговор, в силу которого виновный будет исключен из их среды, так как подобного рода преступления община никогда не наблюдала. Падчерица избрала первое, т.е. дала делу надлежащий ход. Виновный был приговорен к трехлетнему тюремному заключению, после чего община стала считать себя удовлетворенной»³. Вышеописанные эпизоды из повседневной сельской жизни свидетельствуют о том, что влияние обычного права и общинных установок было определяющим в формировании правового сознания крестьян.

Одним из основных принципов народного правового сознания был постулат «глядя по человеку и по хозяйству», который соответствовал идеалу общинного устройства «чтобы никому не было обидно». При этом крестьяне твердо верили, что Бог карает за все преступления, совершенные людьми, особенно же за те, которые остаются безнаказанными по человеческому суду. Например, В.В. Тенишев приводит рассказ, «как во время угощения крестьян деревни Шоховки Брянского уезда водкой за работу два крестьянина, отец с сыном, были недовольны на приказчика Якова. Они посчитали, что получили водки меньше других, и из мести тут же убили его. Убийство осталось нераскрытым. Но 14-летняя дочь убийцы слышала стоны Якова и сошла с ума от ужаса. Жена убийцы была в это время беременна, и у родившегося затем ребенка была вся нижняя часть лица сине-багровая, так что крестьяне говорили, что на лице сына воспоминания о невинно пролитой крови Якова. Через три года убийцу постигло новое горе. Его сын, который вместе с ним убивал Якова, был убит в лесу подрубленным деревом» [7, с. 132].

\footnotetext{
${ }^{2}$ ГАРФ. Ф. 586. Оп. 1. Д. 109. Л. 4.

${ }^{3}$ Там же. л. 21.
} 
Информаторы с мест подтверждали, что крестьянская вера в неизбежность божьей кары была общераспространенной. Так, С. Гришин сообщал, что «оставшихся не наказанных судом Бог наказывает. Каре Божьей приписывают смерть человека, члена семьи виноватого, падеж скота его, упадок по хозяйству, отдача детей в службу» ${ }^{4}$. А. Титов: «Убеждение, что Божья кара постигнет преступника, очень твердо в народе ${ }^{5}$. А. Кушнерев описывал красноречивый случай, в котором переплелись как уважение к церкви, так и страх перед высшим наказанием: «Нынешним летом (1899 г.) у священника с. Васильевского увезли несколько досок. Ктото заявил потерпевшему, что кражу у него совершил крестьянин деревни Холмины, но при обыске досок этих у означенного крестьянина не нашли, однако священник был почему-то уверен, что кражу совершил именно подозреваемый крестьянин. После обыска священник призвал подозреваемого вора в церковь и начал усовещевать его сознаться в проступке. Последний упорно стоял на своем, что он досок не крал. Тогда священник предложил ему поклясться перед иконой, что он не увозил досок. Крестьянин смутился и сознался в преступлении, а вскоре после этого привез священнику ночью, чтобы никто не видал, и увезенные у него доски, которые были спрятаны им у родственника в соседней деревне» ${ }^{6}$.

При рассмотрении криминологических аспектов необходимо учитывать, что у крестьян существовало отрицательное отношение к неудавшимся преступлениям. Корреспондент С. Гришин отмечал: «Покушение на преступление не наказывается судом, но наказывается народом. Пытающегося украсть лошадь или имущество в случае поимки бьют сильно и отпускают... Сидевшего в тюрьме всем ограничивают, во всем ему упрек «острожник» и ему всегда приходится молчать, и семья угнетена, ее тоже упрекают, но это только за кражи между самими крестьянами, а за кражи у посторонних лиц считают, что господа и правого посадят, потому к осужденным относятся даже сочувственно» ${ }^{7}$. В Смоленской губернии «к людям, бывшим под судом, народ относился с недоверием и при всяком случае называл острожником, вором и т.п.

\footnotetext{
${ }^{4}$ ГАРФ. Ф. 586. Оп. 1. Д. 114. Л. 41.

${ }^{5}$ Там же. Д. 120. л. 9.

${ }^{6}$ Там же. л. 110.

7 Там же. Д. 114. л. 42.
}

Лица, бывшие под судом, считались членами общества, но они не могли избираться ни на какую общественную должность» ${ }^{8}$.

Однако в отношении к таким людям тоже была своя специфика. Так, информатор Лебедев из Калужской губернии сообщал: «Лица, бывшие под уголовным судом и оправданные им, считаются такими же равноправными членами общества, какими они были до суда, и никаким ограничениям не подвергаются. Лица, которые оправданы судом как невиновные, но среди общества считаются виновными в преступлении, не пользуются симпатией народа и страдают от его притеснений ${ }^{9}$. Информатор И. Гринев из Смоленской губернии отмечал: «Попытку совершить преступление народ не считает за преступление. Вообще угрозам не придают никакого значения. На тех лиц, которые указывают преступление, преступника или на вещи, забытые преступлением, народ смотрит с уважением, и даже как на героев, которые в будущем могут сильно пострадать от преступников ${ }^{10}$.

Своеобразное крестьянское понимание законности представляло собой «причудливое сочетание действительно существующих норм и норм, желательных для крестьян» [10, с. 18-19]. В частности, это представление ясно отразилось в крестьянских взглядах на лесные богатства. Крестьяне считали, что лес - общее достояние, принадлежит всем, но такие взгляды противоречили формальной законности. В результате порубки в казенном лесу с крестьянской точки зрения не считались преступлением именно потому, что народ смотрел на казенный лес как на общую собственность.

Вышеописанное отношение подтверждает письмо из Лесного департамента за 1902 г., где сообщалось, что в Строительной слободе Брянского уезда крестьяне стремились «сохранить за собою право свободного доступа в казенный лес для самовольных порубок. Бороться со злом самовольных порубок и похищения казенного леса арендаторам названной оброчной статьи представляется особенно затруднительным... Для охранения казенного леса является необходимым поселение в Акулицкой даче лесной стражи...» ${ }^{11}$. Информатор Лашманов из Калуж-

\footnotetext{
${ }^{8}$ ГАРФ. Ф. 586. Оп. 1. Д. 120. Л. 58.

${ }^{9}$ Там же. Д. 109. Л. 25.

${ }^{10}$ Там же. Д. 120. Л. 57.

11 Государственный архив Орловской области.
} Ф. 580. Ст. 2. Д. 2947. Л. 40-41 об. 
ской губернии по этому поводу отмечал: «Крестьяне не считают за преступление лесные порубки и даже кражи лесного материала, мелких хозяйственных принадлежностей: веревок, подков, ломов, лопат и пр., если эти покражи делаются у лиц, состоящих, например, на фабрике, заводе, у богатого землевладельца и пр. Наоборот, покража этих предметов у крестьянина же никогда не оставляется без наказания ${ }^{12}$.

Для создания более объективной картины необходимо отметить, что такое отношение к похищению леса можно оправдать тем, что лесные массивы были весьма обширны и их переход в чью-либо частную собственность выглядел по меньшей мере странно. Весьма образно по этому поводу в 1899 г. высказалась информатор М.И. Михеева: «Лесные порубки народ не считает преступлением: «Если бы господа рубили, им это с жиру и с толстого мяса делать, - рассуждают мужики, - а нашему брату где ж что взять-то на разные протари (нужды)». Еще говорят так: «Не он срубит, так другой - кормиться чем-нибудь надо» ${ }^{13}$.

Важно учитывать, что в сельской повседневности всё имело свою материальную ценность. Однако и здесь были специфические особенности. Так, по обоснованному мнению В.Б. Безгина, «любой проступок в деревне получал, прежде всего, моральную оценку» [25, с. 32]. При этом криминологические аспекты правового сознания крестьян были важной, но далеко не единственной гранью повседневности деревни [26].

Ярким проявлением криминологической составляющей правового сознания крестьян Западного региона России были самосуды. Самосуд длительное время сохранялся и применялся в крестьянском быту. Исследователь В.В. Тенишев под самосудом понимал «такое осуществление судебной власти, которое не предусмотрено законом и производится самовольно. Решения, также поставленные самовольно, приводятся в исполнение порядком, не предусмотренным законом, в большинстве случаев насильственно» [8, с. 33].

Указанные народные расправы на рубеже XIX-XX вв. часто заканчивались ежегодными убийствами. Решение о самосуде принималось, как правило, на сходе домохозяевами 35-40 лет во главе со старостой. Приговор выносился

\footnotetext{
12 ГАРФ. Ф. 586. Оп. 1. Д. 109. Л. 3.

${ }^{13}$ Там же. Д. 114. л. 127.
}

втайне от местных властей, чтобы они своим вмешательством не препятствовали расправе. Священник Птицын в 1897 г. по этому поводу сообщал: «С ворами и конокрадами крестьяне распоряжаются по-своему и могут убить совсем, если был вовремя пойман, а увечье часто бывает таким людям. Женщинам не делается снисхождения. На пойманного вора с хомутом надевают на него иногда и водят по деревне с криком и делают побои. Известного вора часто крестьяне не принимают к себе на поруки, а ссылают в ссылку. Случаи убийства очень редки, и если кто учинит его, то всё село считает себя обиженным, выражаясь так: «Вот злодей наделал поклеп всему миру, из-за него будут таскать по судам - свети глазами ${ }^{14}$.

По мнению А.М. Смирнова, «самовольная расправа над ворами, особенно конокрадами и поджигателями, а также самосуд на почве суеверия были нормой для жителей российских деревень...» [27, с. 40]. Трудно спорить с очевидным утверждением автора, однако крестьянская община с помощью самосуда пресекала действия, которые грозили нарушить традиционный уклад жизни и хозяйства.

Крестьянское правосознание проявлялось в двойном стандарте, в оценке правонарушений в системе «свой - чужой». Мужик не признавал со своей стороны предосудительным, несправедливым делом кражу или обман по отношению ко всякому, кто не свой брат крестьянин. Информатор С. Гришин отмечал: «В сравнении с мелкими кражами у помещиков грех считается важнее. Потому что кражи эти они ничуть не осуждают, а, наоборот, приписывают их заботливости хозяина, выражаясь так: «Вот Гришка Балалаев ночи не спал, зато двор переделал, и хворост и слеги у него не купленные ${ }^{15}$. Воровство у помещиков крестьяне не считали преступлением, что говорит об ограниченном действии обычного права, его замыкании в общинных рамках.

Таким образом, изучение криминологических аспектов правового сознания крестьянства Западного региона России на рубеже XIX-XX вв. позволяет говорить о преобладании традиционализма в сельской жизни. Правовое сознание находило свое выражение в нормах обычного права, которым руководствовались крестьяне Западного региона России. В народной жизни

\footnotetext{
${ }^{14}$ ГАРФ. Ф. 586. Оп. 1. Д. 114. Л. 6.

${ }^{15}$ Там же. Л. 40-41.
} 
обычаи выступали хранителями многовекового правового опыта. Поэтому крестьяне старались относиться к ним бережно, так как считали: что древнее, то правее.

Для правового сознания крестьян были характерны индивидуализм и субъективизм, что на практике проявлялось в отсутствии формализма. Правовые принципы существовали слитно с религиозными и нравственными, что приводило к стремлению крестьян решать все вопросы миром, чтобы никому не было обидно. Для этого использовались различные правовые способы: грех пополам, глядя по человеку и по хозяйству, божба, жребий и др. Очевидно, что крестьяне с законом были знакомы, но большинство правовых предписаний не соответствовало условиям народной жизни, что и приводило к нарастанию противоречий в этой сфере. Ярким примером криминологических аспектов правового сознания крестьян можно считать отношение к лесопо- рубкам - их не воспринимали как серьезное преступление.

Крестьянское правовое сознание в первую очередь выражалось в отношении к различным проступкам. Больше всего ценился человеческий труд, вложенный в какую-либо вещь. Существовал двойной стандарт - свои братья-крестьяне и чужие, у которых не грех и воровать. Частная собственность имела весьма слабое развитие, поэтому часто имущественные преступления вовсе не преследовались. Несмотря на стихийность, было весьма организованным такое явление, как самосуд, так как он часто совершался с разрешающей санкции общины и местной власти. Применению самосудов в сельской местности способствовали частые случаи конокрадства и банальное воровство. При этом сохранялись консерватизм и архаичность правового сознания сельского населения. В итоге подавляющее большинство крестьян придерживалось традиций и обычаев, выработанных веками.

\section{СПИСОК ИСПОЛЬЗОВАННОЙ ЛИТЕРАТУРЫ}

1. Фарбер И.Е. Правосознание как форма общественного сознания / И.Е. Фарбер. - М. : Юрид. лит., 1963. - 206 с.

2. Остроумов Г.С. Правовое осознание действительности / Г.С. Остроумов. - М. : Наука, 1969. - 175 с.

3. Большой энциклопедический словарь / гл. ред. А.М. Прохоров. - М. : Большая Рос. энцикл. ; СПб. : Норинт, 1997. $1456 \mathrm{c}$.

4. Блок М. Апология истории, или Ремесло историка / М. Блок. - М. : Наука, 1986. - 174 с.

5. Даль В. Пословицы русского народа : в 2 т. / В. Даль. - М. : Худож. лит., 1984. - Т. 2. - 400 с.

6. Тенишев В.В. Административное положение русского крестьянина / В.В. Тенишев. - СПб. : Тип. А.С. Суворина, 1908. $-172 \mathrm{c}$

7. Тенишев В.В. Общие начала уголовного права в понимании русского крестьянина / В.В. Тенишев // Журнал Министерства юстиции. - 1909. - № 7. - С. 119-158.

8. Тенишев В.В. Правосудие в русском крестьянском быту / В.В. Тенишев. - Брянск : Тип. Л.И. Итина и Ко, 1907. - 192 с.

9. Социально-политическое и правовое положение крестьянства в дореволюционной России / отв. ред. В.Т. Пашуто. Воронеж : Изд-во Воронеж. ун-та, 1983. - 270 с.

10. Кабытов П.С. Русское крестьянство: этапы духовного освобождения / П.С. Кабытов, В.А. Козлов, Б.Г. Литвак. - М. : Мысль, 1988. - 122 с.

11. Белканов Е.А. Структура и функции правосознания : дис. ... канд. юрид. наук : 12.00 .01 / Е.А. Белканов. - Екатеринбург, 1996. - 200 с.

12. Малахов В.П. Природа, содержание и логика правосознания : дис. ... д-ра юрид. наук : 12.00 .01 / В.П. Малахов. М., 2001. -502 c.

13. Менталитет и аграрное развитие России (XIX-XX вв.) : материалы междунар. конф., Москва, 14-15 июня 1994 г. / отв. ред. В.П. Данилов, Л.В. Милов. - М. : Рос. полит. энцикл., 1996. - 439 с.

14. Громыко М.М. Мир русской деревни / М.М. Громыко. - М. : Молодая гвардия, 1991. - 269 с.

15. Benson B.L. Customary Law / B.L. Benson // Encyclopedia of Law and Economics. - 2014. - June 21. - P. 1-10.

16. Buxbaum D.C. Family Law and Customary Law in Asia: A Contemporary Legal Perspective / D.C. Buxbaum. - Springer Netherlands, 1968. - $228 \mathrm{p}$.

17. Kelsen H. General Theory of Law and State / H. Kelsen. - Cambridge : Harvard Univ. Press, 1945. - 516 p.

18. Parisi F. Customary Law / F. Parisi // The Encyclopedia of Public Choice. - 2004. - № 1. - P. 460-463.

19. Roughan N. The Nature of Customary Law / N. Roughan // Res Publica. - 2009. - Vol. 15, iss. 3. - P. 305-313.

20. Фрэнк С. Народная юстиция, община и культура русского крестьянства. 1870-1900 [Электронный ресурс] / C. Фрэнк. - Режим доступа: http://ec-dejavu.ru/m/Mob_murder.html.

21. Бербанк Д. Правовая культура, гражданство и крестьянская юриспруденция: перспективы начала XX в. / Д. Бербанк // Американская русистика: вехи историографии последних лет. Императорский период : антология. - Самара : Самар. ун-т, 2000. - С. 243-265.

22. Бербанк Д. Правовая реформа и правовая культура: непризнанный успех волостных судов в имперской России / Д. Бербанк // Известия высших учебных заведений. Правоведение. - 2003. - № 2. - С. 188-196. 
23. Шанин Т. Русское крестьянское право и наследование имущества / Т. Шанин // Отечественные записки. - 2003. № 2. - С. 337-347.

24. Александров В.А. Русские / В.А. Александров, И.В. Власова, Н.С. Полищук. - М. : Наука, 1999. - 828 с.

25. Безгин В.Б. Обычное право русской деревни (вторая половина XIX - начало XX в.) : учеб. пособие / В.Б. Безгин. Тамбов : Изд-во Тамб. гос. техн. ун-та, 2000. - 48 с.

26. Кулачков В.В. Правовая повседневность крестьянства Западного региона России в первой трети XX века / В.В. Кулачков. - Брянск : Ладомир, 2012. - 166 с.

27. Смирнов А.М. Самосуд в России как социально-правовой феномен: криминологический анализ и меры профилактики / А.М. Смирнов // Криминологический журнал Байкальского государственного университета экономики и права. 2012. - № 1 (19). - С. 39-43.

\section{REFERENCES}

1. Farber I.E. Pravosoznanie kak forma obshchestvennogo soznaniya [Legal Consciousness as a Form of Public Consciousness]. Moscow, Yuridicheskaya literatura Publ., 1963. 206 p.

2. Ostroumov G.S. Pravovoe osoznanie deistvitel'nosti [Legal Understanding of Reality]. Moscow, Nauka Publ., 1969. 175 p.

3. Prokhorov A.M. (ed.). Bol'shoi entsiklopedicheskii slovar' [The Great Encyclopedic Dictionary]. Moscow, Bol'shaya Rossiiskaya Entsiklopediya Publ., Saint Petersburg, Norint Publ., 1997. 1456 p.

4. Blok M. Apologiya istorii, ili Remeslo istorika [Apology for History, or the Craft of a Historian]. Moscow, Nauka Publ., 1986. $174 \mathrm{p}$.

5. Dal V. Poslovitsy russkogo naroda [Idioms of the Russian People]. Moscow, Khudozhestvennaya literatura Publ., 1984. Vol. 2. 400 p.

6. Tenishev V.V. Administrativnoe polozhenie russkogo krest'yanina [The Administrative Situation of a Russian Peasant]. Saint Petersburg, A.S. Suvorin Publ., 1908. 172 p.

7. Tenishev V.V. The common basics of criminal law in the understanding of a Russian peasant. Zhurnal Ministerstva yustitsii = Journal of the Ministry of Justice, 1909, no. 7, pp. 119-158. (In Russian).

8. Tenishev V.V. Pravosudie v russkom krest'yanskom bytu [Justice in Russian Peasants' Lives]. Bryansk, L.I. Itin i Ko Publ., 1907. $192 \mathrm{p}$.

9. Pashuto V.T. (ed.). Sotsial'no-politicheskoe i pravovoe polozhenie krest'yanstva v dorevolyutsionnoi Rossii [Socio-Political and Legal Status of Peasants in Pre-Revolutionary Russia]. Voronezh University Publ., 1983. 270 p.

10. Kabytov P.S., Kozlov V.A., Litvak B.G. Russkoe krest'yanstvo: etapy dukhovnogo osvobozhdeniya [Russian Peasantry: the Stages of Spiritual Liberation]. Moscow, Mysl Publ., 1988. 122 p.

11. Belkanov E.A. Struktura i funktsii pravosoznaniya. Kand. Diss. [The structure and functions of legal consciousness. Cand. Diss.]. Yekaterinburg, 1996. 200 p.

12. Malakhov V.P. Priroda, soderzhanie i logika pravosoznaniya. Dokt. Diss. [The nature, content and logics of legal consciousness. Doct. Diss.]. Moscow, 2001. 502 p.

13. Danilov V.P., Milov L.V (eds). Mentalitet i agrarnoe razvitie Rossii (XIX-XX vv.). Materialy mezhdunarodnoi konferentsii, Moskva, 14-15 iyunya $1994 \mathrm{~g}$. [The Mentality and Agricultural Development of Russia (XIX-XX centuries). International Conference Materials. Moscow, June 14-15, 1994]. Moscow, Rossiiskaya politicheskaya entsiklopediya Publ., 1996. 439 p.

14. Gromyko M.M. Mir russkoi derevni [The World of Russian Village]. Moscow, Molodaya gvardiya Publ., 1991. 269 p.

15. Benson B.L. Customary Law. Encyclopedia of Law and Economics, 2014, June 21, pp. 1-10. $228 \mathrm{p}$.

16. Buxbaum D.C. Family Law and Customary Law in Asia: A Contemporary Legal Perspective. Springer Netherlands, 1968.

17. Kelsen H. General Theory of Law and State. Cambridge, Harvard University Press, 1945. 516 p.

18. Parisi F. Customary Law. The Encyclopedia of Public Choice, 2004, no. 1, pp. 460-463.

19. Roughan N. The Nature of Customary Law. Res Publica, 2009, vol. 15, iss. 3, pp. 305-313.

20. Frenk S. Narodnaya yustitsiya, obshchina i kul'tura russkogo krest'yanstva. 1870-1900 [People's justice, community and culture of Russian peasants. 1870-1900]. Available at: http://ec-dejavu.ru/m/Mob_murder.html. (In Russian).

21. Burbank J. Legal Culture, Citizenship, and Peasant Jurisprudence: Perspectives from the Early Twentieth Century. In Solomon P.H. (Jr.) (ed.). Reforming Justice in Russia, 1864-1996: Power, Culture, and the Limits of Legal Order. Armonk, New York, 1997, pp. 82-106. (Russ. ed.: Berbank D. Pravovaya kul'tura, grazhdanstvo i krest'yanskaya yurisprudentsiya: perspektivy nachala XX v. Amerikanskaya rusistika: vekhi istoriografii poslednikh let. Imperatorskii period. Antologiya. Samara University Publ., 2000, pp. 243-265).

22. Burbank J. Russian Peasants Go to Court: Legal Culture in the Countryside, 1905-1917. Bloomington, Indiana University Press, 2004. 400 p. (Russ. ed.: Berbank D. Pravovaya reforma i pravovaya kul'tura: nepriznannyi uspekh volostnykh sudov v imperskoi Rossii. Izvestiya Vysshikh Uchebnykh Zavedenii. Pravovedenie, 2003, no. 2, pp. 188-196).

23. Shanin T. Russian peasants' law and inheritance of property. Otechestvennye zapiski = Russian Essays, 2003, no. 2, pp. 337-347. (In Russian).

24. Aleksandrov V.A., Vlasova I.V., Polishchuk N.S. Russkie [Russians]. Moscow, Nauka Publ., 1999. 828 p.

25. Bezgin V.B. Obychnoe pravo russkoi derevni (vtoraya polovina XIX - nachalo XX v.) [Common Law in the Russian Village (second half of the $19^{\text {th }}-$ early $20^{\text {th }}$ centuries)]. Tambov Institute of Chemical Engineering Publ., $2000.48 \mathrm{p}$.

26. Kulachkov V.V. Pravovaya povsednevnost' krest'yanstva Zapadnogo regiona Rossii v pervoi treti XX veka [Everyday legal realities of peasants' lives in the Western region of Russia in the first third of the $20^{\text {th }}$ century]. Bryansk, Ladomir Publ., 2012. $166 \mathrm{p}$. 
27. Smirnov A.M. Extrajudicial execution in Russia as a socio-legal phenomenon: criminological analysis and prevention measures. Kriminologicheskii zhurnal Baikal'skogo gosudarstvennogo universiteta ehkonomiki $i$ prava = Criminology Journal of Baikal National University of Economics and Law, 2012, no. 1 (19), pp. 39-43. (In Russian).

\section{ИНФОРМАЦИЯ ОБ АВТОРАХ}

Кулачков Вадим Витальевич - доцент кафедры философии, истории и социологии Брянского государственного инженерно-технологического университета, кандидат исторических наук, бакалавр юриспруденции, г. Брянск, Российская Федерация; e-mail:vad2517@ yandex.ru.

Музычук Татьяна Леонидовна - проректор по научной работе Байкальского государственного университета, доктор филологических наук, доцент, г. Иркутск, Российская Федерация; e-mail: muzychuk@rambler.ru.

\section{ДЛЯ ЦИТИРОВАНИЯ}

Кулачков В.В. Криминологические аспекты правового сознания крестьянства Западного региона России на рубеже XIX-XX веков / В.В. Кулачков, Т.Л. Музычук // Всероссийский криминологический журнал. - 2017. T. 11, № 3. - C. 615-622. - DOI: 10.17150/25004255.2017.11(3).615-622.

\section{INFORMATION ABOUT THE AUTHORS}

Kulachkov, Vadim V. - Ass. Professor, Chair of Philosophy, History and Sociology, Bryansk State Engineering-Technological University, Ph.D. in History, Bachelor of Laws, Bryansk, the Russian Federation; e-mail: vad2517@yandex.ru.

Muzychuk, Tatyana L. - Vice Rector for Research, Baikal State University, Doctor of Philology, Ass. Professor, Irkutsk, the Russian Federation; e-mail: muzychuk@ rambler.ru.

\section{FOR CITATION}

Kulachkov V.V., Muzychuk T.L. Criminological aspects of legal consciousness of peasants in the Western region of Russia at the turn of the $19^{\text {th }}-20^{\text {th }}$ centuries. Vserossiiskii kriminologicheskii zhurnal = Russian Journal of Criminology, 2017, vol. 11, no. 3, pp. 615-622. DOI: 10.17150/25004255.2017.11(3).615-622. (In Russian). 